\title{
Nano-Calcium Ameliorates Ovariectomy-Induced Bone Loss in Female Rats
}

\author{
Hyeon-Son Choi, JeungHi Han, Seungsik Chung', Yang Hee Hong, and Hyung Joo Suh* \\ Department of Food and Nutrition, Korea University, Seoul 136-703, Korea \\ ${ }^{1} \mathrm{KC}$ Feed Co. Ltd., Yeongcheon 770-805, Korea
}

\begin{abstract}
In this study, we examined the effects of organic types of calcium derived from oyster shell (OS-Ca) and nano-calcium (Nano-Ca) on the bio-availability and physiological responses associated with bone health in ovariectomised rats. Increased body weight, which is one of the physiological effects of ovary removal, was significantly recovered by Nano-Ca treatment $(p<0.05)$. The reduced calcium level in the liver in ovariectomised rat was increased significantly with OS-Ca and Nano-Ca treatment $(p<0.05)$, suggesting improved calcium bio-availability. Alkaline phosphatase (ALP), osteocalcin, and deoxypyridinoline (DPD) were analysed as biochemical markers of bone metabolism and health in the presence or absence of OS$\mathrm{Ca}$ and Nano-Ca. ALP, osteocalcin, and DPD levels increased following ovary removal and tended to decrease after treatment with Nano-Ca, indicating that Nano-Ca induces favourable bone metabolism. This result was reflected in the recovery of bone mineral density (BMD) and bone mineral content (BMC) of the femur after Nano-Ca treatment following ovary removal. Taken together, our data show that the tested calcium treatments, especially using Nano-Ca, enhanced the bioavailability or absorption of calcium and positively affected bone metabolism in ovariectomised rats.
\end{abstract}

Key words: ovariectomy, nano-calcium, calcium bioavailability, bone metabolism

\section{Introduction}

Calcium is one of the most important minerals that regulates various physiological responses at the tissue and cellular levels. It plays an important role in a formation of bone, muscle contraction, coagulation, enzymatic activation, penetration of cell membranes etc. Nearly all (99\%) of the calcium in the body is stored in the bones and teeth, where it has structural and functional roles, respectively (Ross et al., 2011). The remainder of the body's calcium is crucial to physiological functions, such as nerve transmission and intracellular signalling (Ross et al., 2011).

Calcium is not synthesised in human body; it must be absorbed via food. When sufficient amounts are not supplied, calcium is released from bone over time, which can cause fragile bone structure. Bone mass is constantly maintained through a continuing processes of bone formation by osteoblasts and bone resorption by osteoclasts (Datta et al., 2008). The bone remodelling process undergoes changes with age. In childhood, there is more bone

*Corresponding author: Hyung Joo Suh, Department of Food and Nutrition, Korea University, Seoul 136-703, Korea. Tel: 82-2940-2853, Fax: 82-2-940-2859, E-mail:suh1960@korea.ac.kr formation than resorption; whereas in middle adulthood, both processes are maintained equally. However, at older ages, notably in postmenopausal women, bone resorption exceeds formation, leading to bone loss and lower bone density. Calcium imbalance due to dominant resorption over time results in increased risk of bone diseases such as osteoporosis (Datta et al., 2008; Jackson et al., 2006). Osteoporosis is a condition that induces reduced bone density and an enhanced risk of fracture (Datta et al., 2008). The reduction of bone density originates from an excessive loss of bone components and/or insufficient bone formation. It is closely related to reduced calcium intake and a hormone (oestrogen) deficiency (Prentice, 2004). Although lack of oestrogen is a major factor in osteoporosis, a shortage of calcium intake over time also significantly contributes to the occurrence of osteoporosis (Jackson et al., 2006; Prentice, 2004). The sufficient calcium intake in adulthood can help prevent osteoporosis (Prentice, 2004).

However, it is difficult to maintain an optimal calcium intake level in present-day life. Thus, calcium supplements are suggested as an alternative (Straub, 2007). In fact, the utility of a calcium supplement varies in terms of the availability of calcium in the body, which depends on the 
calcium form in the supplement (Straub, 2007). The type of calcium is one of the factors affecting calcium availability and absorption (Gueguen and Pointillart, 2000). Recent studies showed that calcium carbonate, calcium citrate malate (CCM), and casein phosphopeptides (CPP) are the major sources of calcium known to induce efficient absorption of calcium and bone mineralisation (DawsonHughes et al., 1990; Nakashima et al., 2009). Calcium exists in a compound form in food and supplements. Mostly, carbonate or citrate is combined with calcium, which is referred as an element in supplements. Other types of calcium include phosphate, lactate, gluconate, and so on (Gueguen and Pointillart, 2000). The compound is dissolved in the digestive tract, allowing the release of elemental calcium, and is then available to be absorbed in the intestine. One of forms containing high elemental calcium is a carbonate compound. Oyster shell is a natural source of calcium carbonate. Meanwhile, a nano-sized calcium compound has recently received attention for multipurpose uses. The nano-calcium particle size is very small, and it is thought to be much better absorbed and have higher bio-availability (Nakashima et al., 2009).

In this study, we investigated organic calcium materials as sources of calcium supplements for the prevention and treatment of osteoporosis, expecting enhanced bio-availability and favourable bone metabolism based on increased solubility in the body. Our study evaluated the effect of oyster shell calcium (OS-Ca) and nano-calcium (Nano$\mathrm{Ca}$ ) on bio-availability and physiological functions using rats with osteoporosis induced by ovary removal and a lowcalcium diet.

\section{Materials and Methods}

\section{Materials}

Nanonised oyster shell calcium (Nano-Ca) and micronised oyster shell calcium (OS-Ca) were prepared at Apexel Co. Ltd. (Korea) by a novel dry cryo-nanonisation grinding system integrated with a size separator. All reagents and standard solutions used in this study were of reagent grade from Sigma Chemical Co. (USA).

\section{Animals and treatments}

Female Sprague-Dawley (SD, 10-wk-old) rats were obtained from Deahan Biolink Co. Ltd. (Korea). Animals were maintained in $42 \times 28 \mathrm{~cm}$ cages at $22-24^{\circ} \mathrm{C}$ and a humidity of $60 \pm 5 \%$, and the day and night cycle was automatically controlled in the animal house at Korea University. Food and deionised water were supplied ad libitum. The body weight and amount of intake were measured every $7 \mathrm{~d}$. After acclimatisation for $1 \mathrm{wk}$, female SD rats were anesthetised with $2 \%$ isoflurane, and the ovaries were removed bilaterally (Murray, 1936). The ovaries were removed when the average body weight was approximately $250.7 \pm 5$ g. For the Sham group, an abdominal operation was performed without ovary removal. Animals were grouped by random sampling selection with 8 rats per group in a total of 4 groups, as follows: normal control group (normal calcium diet after mock-operation, Sham), ovariectomy control group (low calcium diet after ovariectomy, OVX-C), OS-Ca treatment group (low calcium diet with OS-Ca after ovariectomy, OVX + OS-Ca), and Nano-Ca treatment group (low calcium diet with Nano-Ca after ovariectomy, OVX + Nano-Ca). OA-Ca or Nano-Ca was administered at $40 \mathrm{mg} / \mathrm{d}$ in $1 \mathrm{~mL}$ saline for $4 \mathrm{wk}$. Table 1 shows the experimental groups in this study. A purified diet based on the AIG-93 formula was prepared (Table 2). $\mathrm{CaCl}_{2}$ was purchased from Samchun Chemical Co. Ltd. (Korea). The vitamin mixture (AIN-93-VX) was obtained from Deahan Biolink Co. Ltd. The mineral mix was prepared as AIN-93G-MX-calcium free and was obtained from Deahan Biolink Co. Ltd.

\section{Sample collection}

Animals were sacrificed by etherisation after fasting for $12 \mathrm{~h}$. Blood was collected from the aorta. Serum was obtained from supernatant of the blood after centrifugation at $3,000 \mathrm{~g}$ at $4^{\circ} \mathrm{C}$, and stored at $-70^{\circ} \mathrm{C}$ until analysis. Organs such as the liver, kidney and spleen, and femur were harvested and cleaned with $0.9 \% \mathrm{NaCl}$. Their weights were measured after the elimination of attached fat, muscle, and water. The weight of the organs was expressed as a relative ratio to $100 \mathrm{~g}$ of body weight.

Table 1. Experimental groups in calcium bio-availability study

\begin{tabular}{cccc}
\hline \hline Experimental groups (8 rats/group) & Operation & Diet & Treatment \\
\hline Sham & Mock-operation & Normal calcium diet $(0.5 \%)$ & none \\
OVX-C & Ovariectomy & Low calcium diet $(0.1 \%)$ & none \\
OVX + OS-Ca & Ovariectomy & Low calcium diet $(0.1 \%)$ & OS-calcium $(40 \mathrm{mg} / \mathrm{d})$ \\
OVX + Nano-Ca & Ovariectomy & Low calcium diet $(0.1 \%)$ & Nano-calcium $(40 \mathrm{mg} / \mathrm{d})$ \\
\hline
\end{tabular}


Table 2. Components of experimental diets

\begin{tabular}{ccc}
\hline \hline Ingredient $(\mathrm{g} / 100 \mathrm{~g})$ & Normal diet & $\begin{array}{c}\text { Low calcium } \\
\text { diet }\end{array}$ \\
\hline Corn starch & 39.7 & 39.7 \\
Casein & 20 & 20 \\
Sucrose & 23.5 & 23.5 \\
Soybean oil & 7 & 7 \\
Cellulose & 5 & 5 \\
L-methionine & 0.3 & 0.3 \\
Vitamin mixture $^{1)}$ & 1 & 1 \\
Mineral mixture (calcium free) $^{2)}$ & 2.2 & 3.22 \\
CaCl & 1.3 & 0.28 \\
Total $(\mathrm{g})$ & 100 & 100 \\
$\mathrm{Ca}(\%)$ & 0.5 & 0.1 \\
\hline
\end{tabular}

${ }^{1)}$ Vitamin mixture: AIN-93G-VX.

${ }^{2)}$ Mineral mixture $(100 \mathrm{~g})$ : AIN-93G-MX-calcium free $\left(\mathrm{KH}_{2} \mathrm{PO}_{4}\right.$ : 51.44 g, NaH $\mathrm{PO}_{4}: 18.70 \mathrm{~g}, \mathrm{NaCl}: 9.32 \mathrm{~g}, \mathrm{MgSO}_{4}: 14.34 \mathrm{~g}, \mathrm{ZnCO}_{3}$ : $220 \mathrm{mg}, \mathrm{MnSO}_{4} \cdot 4 \mathrm{H}_{2} \mathrm{O}: 240 \mathrm{mg}, \mathrm{CuSO}_{4} \cdot 5 \mathrm{H}_{2} \mathrm{O}: 60 \mathrm{mg}, \mathrm{KI}: 20 \mathrm{mg}$, iron citrate: $6.36 \mathrm{~g})$.

\section{Biochemical assays}

Serum and liver were pre-treated using the wet digestion method. Briefly, $0.25 \mathrm{~g}$ ( $1 \mathrm{~mL}$ ) of samples was digested at $100^{\circ} \mathrm{C}$ for $10 \mathrm{~h}$ in the presence of $5 \mathrm{~mL} 65 \% \mathrm{HNO}_{3}$. Calcium in the serum and liver was analysed using an Optima 2100 DV ICP-OES (PerkinElmer, USA). All equipment was cleaned with $2 \%$ nitric acid for $12 \mathrm{~h}$ and rinsed with distilled water prior to use. Alkaline phosphatase (ALP) and creatine were measured using a FUJI DRICHEM 3500 (Fuji Photo Film Co., Japan) and automatic chemical analyser. Osteocalcin and deoxypyridinoline (DPD) were analysed using a rat osteocalcin ELISA kit (R\&D Systems Inc., USA) and rat DPD ELISA kit (R\&D Systems Inc.), respectively. The mineral density and calcium content in the femur were analysed using dual energy
X-ray absorptiometry (DEXA, PIXImus, USA).

\section{Statistical analysis}

All statistical analyses, including standard error of mean (SEM), were performed using the Statistical Package for Social Sciences version 12.0 (SPSS Inc., USA). The statistical significance of differences was determined using an ANOVA, and detailed post-verification was performed by Duncan's multiple range test at a significance level of $p<0.05$.

\section{Results and Discussion}

\section{Body weight and food intake}

We examined the effects of calcium treatments on food intake and body weight (Fig. 1). Body weight was shown to increase significantly in the ovariectomy groups compared with the Sham group $(p<0.05)$. The increased weight in ovariectomised groups was thought to be a climacteric symptom of ovary removal. Os-Ca treatment resulted in slightly lower body weight compared with the ovariectomised group (OVX-C), but the difference was not significant. In Nano-Ca treatment, body weight was significantly decreased compared to the ovariectomised group (OVX-C) $(p<0.05)$, suggesting that Nano-Ca intake can improve a menopausal symptom derived from ovary removal.

This result correlates with other studies, which showed a relationship between calcium intake and body weight (Jacqmain et al., 2003; Zemel, 2002). Food intake was shown to increase in ovariectomised groups compared with the Sham group. In particular, the Os-Ca-treated group $(23.22 \mathrm{~g} / \mathrm{d})$ showed a significant increase in daily food

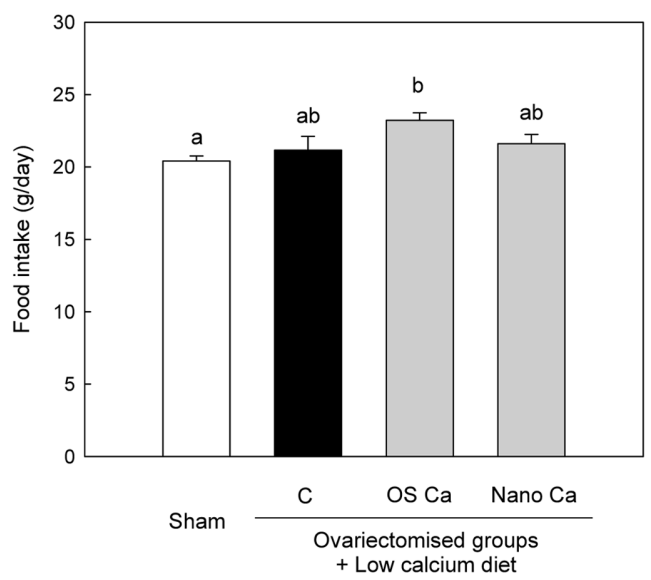

Fig. 1. Body weight gain (A) and food intake (B) of experimental groups. Values are mean \pm SEM for 8 rats. Means with different superscripted letters are significantly different at $p<0.05$ by Duncan's multiple range test. Sham: normal calcium diet after mock-operation, OVX-C: low calcium diet after ovariectomy, OVX + OS-Ca: low calcium diet with oyster shell calcium after ovariectomy, OVX + Nano-Ca: low calcium diet with nano-calcium after ovariectomy. 

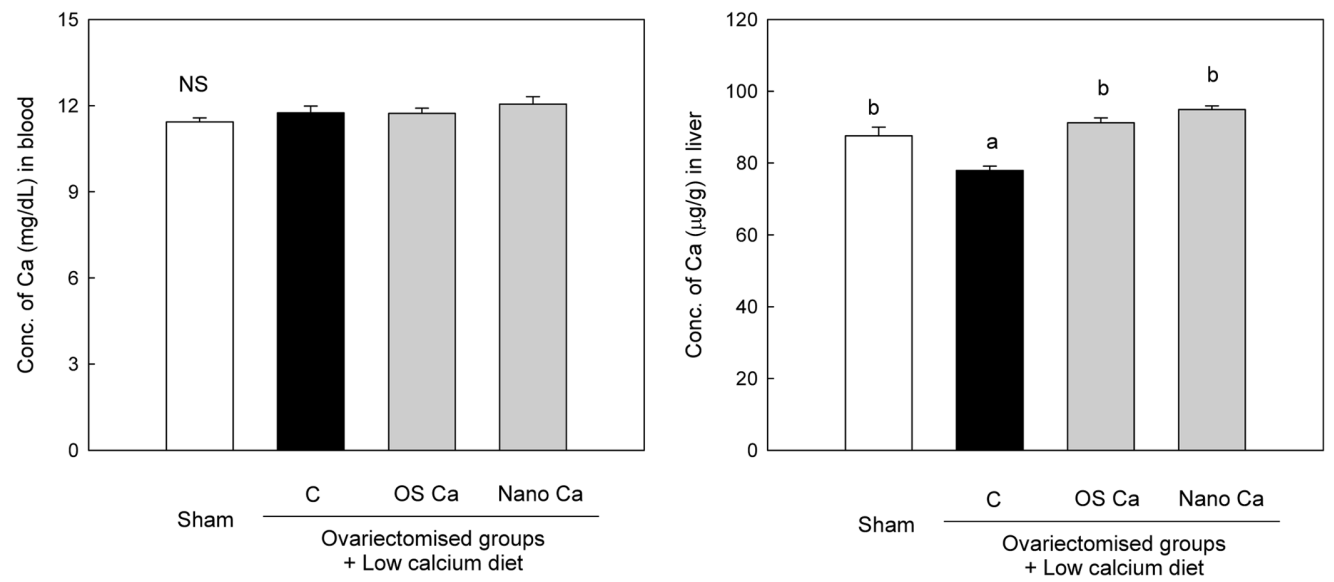

Fig. 2. Calcium levels in blood (A) and liver (B) of ovariectomised SD rats treated with various calcium types for 5 wk. Values are mean \pm SEM for 8 rats. Means with different superscripted letters are significantly different at $p<0.05$ by Duncan's multiple range test. NS: not significant. Sham: normal calcium diet after mock-operation, OVX-C: low calcium diet after ovariectomy, OVX + OS-Ca: low calcium diet with oyster shell calcium after ovariectomy, OVX + Nano-Ca: low calcium diet with nano-calcium after ovariectomy.

intake compared with the Sham group $(20.42 \mathrm{~g} / \mathrm{d})(p<$ $0.05)$. Many studies reported an increase in body weight due to ovary removal (Okazaki et al., 2002; Zemel, 2002). Ovary removal reduces the levels of oestrogen, a sex hormone, which plays an important role in the inhibition of adipocyte differentiation. Thus, oestrogen deficiency is thought to increase lipid accumulation by promoting adipocyte differentiation, contributing to increased body weight (Grün and Blumberg, 2009). However, Kalu et al. (1989) reported that increased body weight due to ovary removal resulted from increased food intake rather than an oestrogen shortage. In addition, numerous studies reported an increase in body weight due to low calcium intake (Zhao et al., 2011). Our data indicated that calcium intake via Os-Ca or Nano-Ca can ameliorate the increase in body weight caused by oestrogen deficiency.

\section{Organ weight and calcium concentration}

To determine whether the change in body weight after calcium treatment is connected to the weights of organs, we investigated the effects of calcium treatment on the weights of the liver, spleen, and kidney (Table 3). The weights of the liver and spleen were not significantly changed by ovary removal and calcium treatment. However, the kidney weight tended to decrease after ovary removal, but the administration of calcium did not affect its weight. In
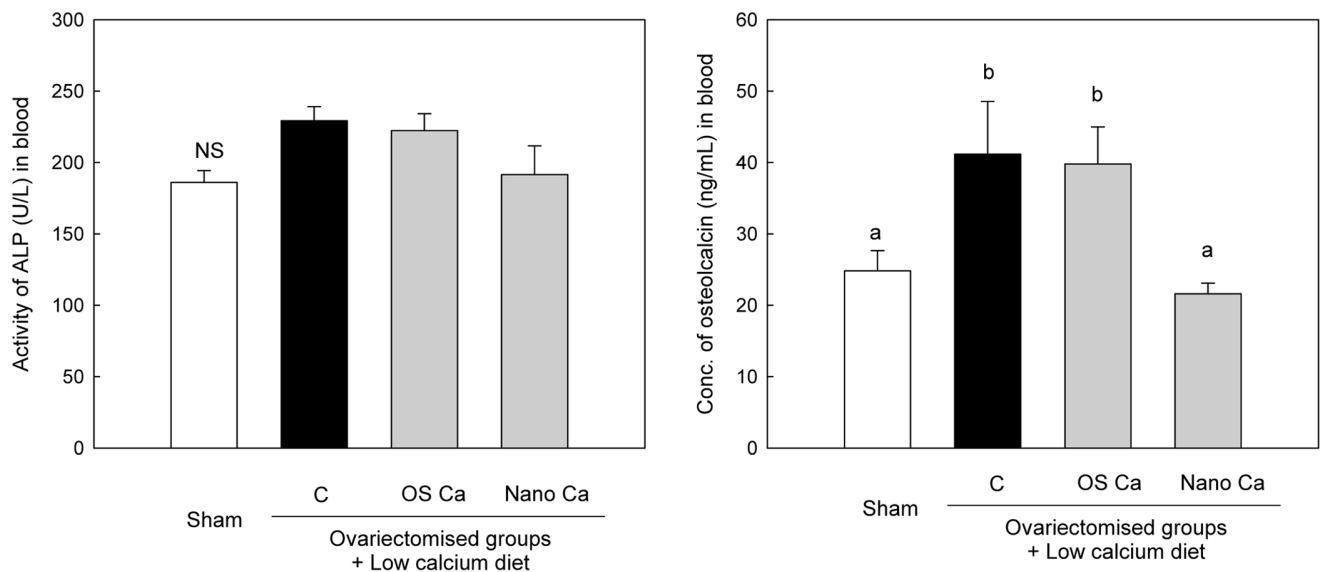

Fig. 3. Bone formation biomarkers (A: alkaline phosphatase (ALP), B: osteocalcin) of ovariectomised SD rats treated with various calcium types for $5 \mathrm{wk}$. Values are mean \pm SEM for 8 rats. Means with different superscript letters are significantly different at $p<0.05$ by Duncan's multiple range tests. NS: not significant. Sham: normal calcium diet after mock-operation, OVX-C: low calcium diet after ovariectomy, OVX + OS-Ca: low calcium diet with oyster shell calcium after ovariectomy, OVX + Nano-Ca: low calcium diet with nano-calcium after ovariectomy. 
Table 3. Relative internal organ weights of ovariectomised SD rats treated with various calcium types for 5 wk

\begin{tabular}{cccc}
\hline \hline Groups & \multicolumn{2}{c}{ Relative organ weight $(\mathrm{g} / 100 \mathrm{~g}$ BW) } \\
\cline { 2 - 5 } & Liver & Spleen & $0.23 \pm 0.01^{\mathrm{NS}}$ \\
Sham & $2.62 \pm 0.05^{\mathrm{NS}}$ & $0.24 \pm 0.02$ & $0.65 \pm 0.04^{\mathrm{ab}}$ \\
OVX-C & $2.66 \pm 0.11$ & $0.34 \pm 0.01$ & $0.60 \pm 0.04^{\mathrm{a}}$ \\
OVX +OS-Ca & $2.77 \pm 0.13$ & $0.26 \pm 0.11$ & $0.66 \pm 0.04^{\mathrm{ab}}$ \\
\hline
\end{tabular}

Values are means \pm SEM for 8 rats. Means with different superscripted letters in a column are significantly different at $p<0.05$ by Duncan's multiple range test. NS: not significant. Sham: normal calcium diet after mock-operation, OVX-C: low-calcium diet after ovariectomy, OVX + OS-Ca: low-calcium diet with oyster shell calcium after ovariectomy, OVX + Nano-Ca: low-calcium diet with nano-calcium after ovariectomy.

the ovary removal model, calcium intake results in weight changes in the organs. Lee et al. (2011) reported that low calcium intake after ovary removal significantly changes the weight of spleen.

The calcium level in the blood did not show any significant difference among the experimental groups; the level was normal (7.2-13 mg/dL) in all groups (Fig. 2). A number of studies showed no difference in the level of calcium in the blood when various levels of calcium supplements were administered to rats with osteoporosis (Choi, 1996; Hietala, 1993). Calcium homeostasis is balanced by calcium metabolic hormones such as the parathyroid hormone and calcitonin (Mundy and Guise, 1999).

The calcium level in the liver was decreased by ovary removal (Fig. 2). However, OS-Ca or Nano-Ca treatment increased the liver calcium level in the ovariectomised groups, with the Nano-Ca group showing the highest increase. This result showed that the bio-availability and absorption of calcium depends on the type of calcium compound, specifically on the molecular weight of the compound.

The oral administration of nanonised pearl powder was found to result in better long-term absorption of calcium, higher gain in body weight, and higher gains in the weight and length of rat femurs than that micronised pearl powder (Cui et al., 2005; Gao et al., 2008).

\section{Bone metabolism markers bone mineral density (BMD) and bone mineral content (BMC) of the femur} Bone remodelling constantly occurs in the body through bone formation by osteoblasts and bone resorption by osteoclasts. We examined effects of calcium treatment on bone formation markers such as ALP and osteocalcin (Fig. 3). ALP, a biochemical marker for bone-forming activity, is associated with the mineralisation of osteoblasts. Many studies reported increased ALP activity in osteoporotic and ovariectomised patients (Arjmandi et al., 2000; Ostrowska et al., 2002). The other marker for bone turnover is osteo- calcin. Osteocalcin contains a vitamin K-dependent $\gamma$-carboxyglutamic acid (Gla) residue responsible for calcium binding and is also involved in bone mineralisation. Osteocalcin is formed in osteoblasts and becomes trapped in the bone matrix. Some is released to blood and can be analysed. It is known to increase in abnormal bone metabolic conditions (Sikavitsas et al., 2001). The levels of ALP and osteocalcin tended to be higher in the ovariectomised group with a low calcium diet (OVX-C) compared with Sham group, suggesting that bone metabolic disorders occur after ovary removal. The OS-Ca and Nano-Ca groups showed improvement in the level of ALP and osteocalcin compared with the OVX-C group (Fig. 3). The Nano-Ca group in particular showed a significant decrease in the osteocalcin level compared with the OVX-C group

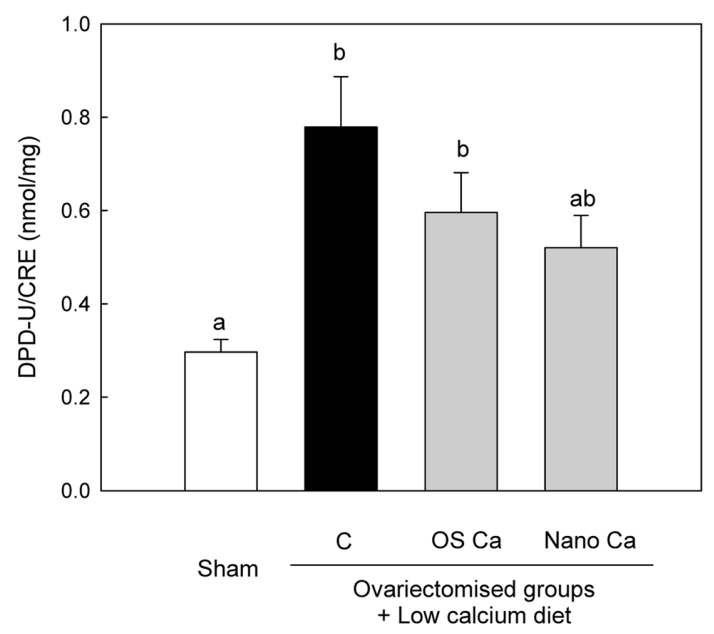

Fig. 4. Bone resorption biomarkers (deoxypyridinoline, DPD) in ovariectomised SD rats treated with various calcium types for $5 \mathrm{wk}$. Values are mean \pm SEM for 8 rats. Means with different superscripted letters are significantly different at $p<0.05$ by Duncan's multiple range test. Sham: normal calcium diet after mock-operation, OVX-C: low calcium diet after ovariectomy, OVX + OS-Ca: low calcium diet with oyster shell calcium after ovariectomy, OVX + Nano-Ca: low calcium diet with nano-calcium after ovariectomy. 

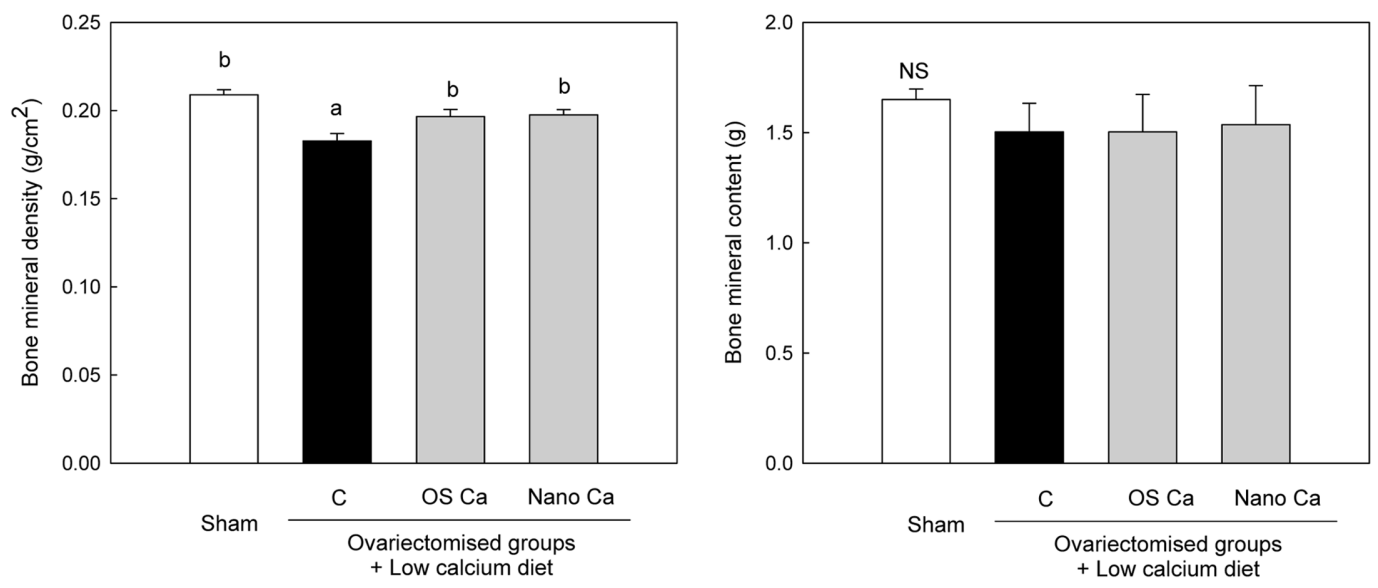

Fig. 5. Femur bone mineral density (BMD) and body mineral content (BMC) of ovariectomised SD rats treated with various calcium types for $5 \mathrm{wk}$. Values are mean \pm SEM for 8 rats. Means with different superscripted letters are significantly different at $p<0.05$ by Duncan's multiple range test. NS: not significant. Sham: normal calcium diet after mock-operation, OVX-C: low calcium diet after ovariectomy, OVX + OS-Ca: low calcium diet with oyster shell calcium after ovariectomy, OVX + Nano-Ca: low calcium diet with nano-calcium after ovariectomy.

$(p<0.05)$. This data correlates with Choi and Lee's study (2008) performed in 8-wk-old ovariectomised rats. In general, an ovariectomy induces an increase in the blood ALP level resulting from the enhancement of bone turnover due to the lack of oestrogen (Marie et al., 1993).

The DPD crosslinking value has been used as a marker for bone diseases, including osteoporosis. It is usually expressed as a ratio of DPD to creatinine. Most DPD levels are found in bone and cartilage. DPD in urine is known to be produced from bone resorption (Robins et al., 1994). Thus, an increase in DPD represents an increase in bone resorption by activated osteoclasts, showing a negative correlation with bone density. In our data, the DPD excretion level was significantly increased by ovary removal $(p<0.05)$, but Nano-Ca treatment restored DPD levels to normal (Fig. 4).

We determined the effects of OS-Ca and Nano-Ca on the bone mineral density (BMD) and bone mineral content (BMC) of the femur (Fig. 5). OS-Ca and Nano-Ca treatment significantly improved the BMD of the femur after ovary removal $(p<0.05)$ (Fig. 5). The BMC of the femur also decreased after ovary removal, but its level did not change after OS-Ca or Nano-Ca treatment. Menopausal osteoporosis exhibits bone metabolism in which bone absorption first occurs, followed by increased bone formation to achieve a balance. Oestrogen deficiency induces an increase in osteoclast activity and bone absorption by increasing bone turnover, eventually generating bone loss through decreased bone formation (Fanti et al., 1998).

Gao et al. (2008) reported that the absorption and utilisation of calcium in rats differs with different sizes of pearl powders. These results strongly support the favourable effect of the two sizes of pearl powders on absorption and utilisation of calcium and bone formation in rats. However, the absorption and utilisation of calcium and bone formation in rats that received nanometre-sized pearl powder was markedly better than that in rats that received micrometre pearl powder. This study therefore strongly suggests that smaller pearl powders could effectively reduce the difficulty of calcium release, increase absorption of calcium and maintain bone normal function in rats.

The above results indicate that the effect of mineral material particle sizes on digestibility and solubility is an important factor that affects their bioavailability. If mineral materials in the alimentary tract are insoluble, they cannot be absorbed. Therefore, when mineral materials are utilised to supply microelements, particle size is very important. Our results also showed Nano-Ca exhibited enhanced bio-availability or absorption of calcium and positively affected bone metabolism in ovariectomised rats.

\section{References}

1. Arjmandi, B. H., Birnbaum, R. S., Juma, S., Barengolts, E., and Kukreja, S. C. (2000) The synthetic phytoestrogen, ipriflavone, and estrogen prevent bone loss by different mechanisms. Calcified Tissue Int. 66, 61-65.

2. Choi, M. J. (1996) The effect of dietary calcium level on biochemical variables of bone metabolism in ovariectomized female rats. J. East Asian Diet Life 6, 295-305.

3. Choi, M. J. and Lee, J. (2008) Effects of caffeine on bone mineral density and bone mineral content in ovariectomized rats. Korean J. Nutr. 41, 216-223.

4. Cui, S., Zhao, Y., Sun, W., Cao, P., and Tang, Q. (2005) Effect 
of nano pearl powder on the calcium absorption and utilization in rats. Acta Laboratorium Animalis Scientia Sinica 13, 204-207.

5. Datta, H. K., Ng, W. F., Walker, J. A., Tuck, S. P., and Varanasi, S. S. (2008) The cell biology of bone metabolism. J. Clin. Pathol. 61, 577-587.

6. Dawson-Hughes, B., Dallal, G. E., Krall, E. A., Sadowski, L., Sahyoun, N., and Tannenbaum, S. (1990) A controlled trial of the effect of calcium supplementation on bone density in postmenopausal women. New Engl. J. Med. 323, 878-883.

7. Fanti, P., Monier-Faugere, M. C., Geng, Z., Schmidt, J., Morris, P. E., Cohen, D., and Malluche, H. H. (1998) The phytoestrogen genistein reduces bone loss in short-term ovariectomized rats. Osteoporosis Int. 8, 274-281.

8. Gao, H., Chen, H., Chen, W., Tao, F., Zheng, Y., Jiang, Y., and Ruan, H. (2008) Effect of nanometer pearl powder on calcium absorption and utilization in rats. Food Chem. 109, 493-498.

9. Grün, F., and Blumberg, B. (2009) Endocrine disrupters as obesogens. Mol. Cell Endocrinol. 304, 19-29.

10. Gueguen, L. and Pointillart, A. (2000) The bioavailability of dietary calcium. J. Am. Coll. Nutr. 19, 119S-136S.

11. Hietala, E. L. (1993) The effect of ovariectomy on periosteal bone formation and bone resorption in adult rats. Bone Miner. 20, 57-65.

12. Jackson, R. D., LaCroix, A. Z., Gass, M., Wallace, R. B., Robbins, J., Lewis, C. E., Bassford, T., Beresford, S. A., Black, H. R., Blanchette, P., Bonds, D. E., Brunner, R. L., Brzyski, R. G., Caan, B., Cauley, J. A., Chlebowski, R. T., Cummings, S. R., Granek, I., Hays, J., Heiss, G., Hendrix, S. L., Howard, B. V., Hsia, J., Hubbell, F. A., Johnson, K. C., Judd, H., Kotchen, J. M., Kuller, L. H., Langer, R. D., Lasser, N. L., Limacher, M. C., Ludlam, S., Manson, J. E., Margolis, K. L., McGowan, J., Ockene, J. K., O'Sullivan, M. J., Phillips, L., Prentice, R. L., Sarto, G. E., Stefanick, M. L., Van Horn, L., WactawskiWende, J., Whitlock, E., Anderson, G. L., Assaf, A. R., and Barad, D. (2006) Calcium plus vitamin D supplementation and the risk of fractures. New Engl. J. Med. 354, 669-683.

13. Jacqmain, M., Doucet, E., Despres, J. P., Bouchard, C., and Tremblay, A. (2003) Calcium intake, body composition, and lipoprotein-lipid concentrations in adults. Am. J. Clin. Nutr. 77, 1448-1452.

14. Kalu, D. N., Liu, C. C., Hardin, R. R., and Hollis, B. W. (1989) The aged rat model of ovarian hormone deficiency bone loss. Endocrinology 124, 7-16.

15. Lee, M. R., Park, M. N., Mun, J. Y., and Lee, Y. S. (2011) Effects of a low calcium diet and oxalate intake on calcium deposits in soft tissues and bone metabolism in ovariectomized rats. Korean J. Nutr. 44, 101-111.

16. Marie, P. J., Hott, M., Modrowski, D., De Pollak, C., Guillemain, J., Deloffre, P., and Tsouderos, Y. (1993) An uncoupling agent containing strontium prevents bone loss by depressing bone resorption and maintaining bone formation in estrogendeficient rats. J. Bone Miner. Res. 8, 607-615.

17. Mundy, G. R. and Guise, T. A. (1999) Hormonal control of calcium homeostasis. Clin. Chem. 45, 1347-1352.

18. Murray, W. S. (1936) Some effects of ovariectomy during the period of declining reproductive powers in mice. J. Exp. Med. 63, 893.

19. Nakashima, S., Yoshie, M., Sano, H., and Bahar, A. (2009) Effect of a test dentifrice containing nano-sized calcium carbonate on remineralization of enamel lesions in vitro. J. Oral Sci. 51, 69-77.

20. Okazaki, R., Inoue, D., Shibata, M., Saika, M., Kido, S., Ooka, H., Tomiyama, H., Sakamoto, Y., and Matsumoto, T. (2002) Estrogen promotes early osteoblast differentiation and inhibits adipocyte differentiation in mouse bone marrow stromal cell lines that express estrogen receptor (ER) alpha or beta. Endocrinology 143, 2349-2356.

21. Ostrowska, Z., Kos-Kudla, B., Marek, B., Kajdaniuk, D., and Ciesielska-Kopacz, N. (2002) Dynamic pattern of IGF-I and chosen biochemical markers of bone metabolism in a rat model of postmenopausal osteoporosis. Endocr. Regul. 36, 9-17.

22. Prentice, A. (2004) Diet, nutrition and the prevention of osteoporosis. Public Health Nutr. 7, 227-243.

23. Robins, S. P., Woitge, H., Hesley, R., Ju, J., Seyedin, S., and Seibel, M. J. (1994) Direct, enzyme-linked immunoassay for urinary deoxypyridinoline as a specific marker for measuring bone resorption. J. Bone Miner. Res. 9, 1643-1649.

24. Ross, A. C., Manson, J. E., Abrams, S. A., Aloia, J. F., Brannon, P. M., Clinton, S. K., Durazo-Arvizu, R. A., Gallagher, J. C., Gallo, R. L., Jones, G., Kovacs, C. S., Mayne, S. T., Rosen, C. J., and Shapses, S. A. (2011) The 2011 report on dietary reference intakes for calcium and vitamin D from the Institute of Medicine: What clinicians need to know. J. Clin. Endocrinol. Metab. 96, 53-58.

25. Sikavitsas, V. I., Temenoff, J. S., and Mikos, A. G. (2001) Biomaterials and bone mechanotransduction. Biomaterials 22, 2581-2593.

26. Straub, D. A. (2007) Calcium supplementation in clinical practice: A review of forms, doses, and indications. Nutr. Clin. Pract. 22, 286-296.

27. Zemel, M. B. (2002) Regulation of adiposity and obesity risk by dietary calcium: Mechanisms and implications. J. Am. Coll. Nutr. 21, 146S-151S.

28. Zhao, Y., Cao, R., Ma, D., Zhang, H., Lappe, J., Recker, R. R., and Xiao, G. G. (2011) Efficacy of calcium supplementation for human bone health by mass spectrometry profiling and cathepsin K measurement in plasma samples. J. Bone Miner. Metab. 29, 552-560.

(Received 2013.7.9/Revised 2013.8.7/Acccepted 2013.8.13) 